\title{
Discretization of flow contain nitrate in porous media by finite volume technique
}

\author{
${ }^{1 *}$ H. R. Vosoughifar, ${ }^{2}$ A. Shamsai and ${ }^{3}$ T. Ebadi \\ ${ }^{1}$ Department of Civil and Environmental Engineering , Islamic Azad University ,South-Tehran Branch, Tehran, Iran \\ ${ }^{2}$ Department of Civil and Environmental Engineering, Sharif University of Technology, Tehran, Iran \\ ${ }^{3}$ Department of Civil and Environmental Engineering, Amir Kabir University of Technology, Tehran, Iran
}

\begin{abstract}
One of the most important pollutants of groudwaters is nitrate. Different human activities including the application of chemical fertilizers in agriculture, causes the emission of nitrate into groudwaters. In this paper, the dynamic effect of soil moisture on carbon and nitrogen cycles has been analyzed by presenting a connection between soil moisture sample and nonlinear differential equations. At present, wide researches are carried out on modeling soil moisture control in solution flows contain nitrate. In order to do so, separation of energy conservation law equations is carried out by a particular method. The mathematical model governing the nitrate containing current in non-isotropic environment has been presented in the form of combined equations. Equation for distribution in multiple environments and Darcy rule has been considered in this model. Then, using finite volume method, separation of flows contain nitrate in porous media is carried out. The current flux is obtained from central difference approximations or upwind approximation. Mashad plain has been considered for case study at this research. Carrying out calibration operation, the measured results have been contrasted with numerical results of finite volume method. After testing the model, it is possible to foresee the way of nitrate changes in other nodes of calculation network. Using these forecasts, the quality of drinking water for several next years is determined. Carrying out numerical modeling by finite volume method, it is found out that the quality of drinking water of Mashad plain would be suitable for the next ten years.
\end{abstract}

Key words: Finite volume, nitrate, porous media, upwind, discretization

*Correponding Author,E.mail: Vosoughifar@Azad.ac.ir

\section{Introduction}

Consumption of drinking water containing chemicals with levels higher than permitted levels causes problems and diseases in human and animal. Among chemicals available in water are nitrates and amino-nitro compounds, the pathogenic effects of which have been confirmed. The nitrate present in well water causes production of the methemoglobin in children blood. Nitrate reduction into nitrite in child's stomach results in nitrate poisoning. Nitrate oxidizes blood hemoglobin and changes it into ferric iron. The hemoglobin iron changes from 2 capacity to 3 capacity and produces a brown pigment called methemoglobin. This new composition is not capable of transferring and releasing oxygen in tissues and causes methemoglobin disease (Rademach, et al., 1992). Using azotic chemical fertilizers such as ammonium sulfate $\left(\left(\mathrm{NH}_{4}\right)_{2} \mathrm{SO}_{4}\right)$, urea $\left(\left(\mathrm{CO}\left(\mathrm{NH}_{4}\right)_{2}\right)\right.$, ammonium carbonate $\left.\left(\mathrm{NH}_{4}\right)_{2} \mathrm{CO}_{3}\right)$, potassium nitrate $\left(\mathrm{KNO}_{3}\right)$, calcium nitrate $\left(\mathrm{Ca}\left(\mathrm{NO}_{3}\right)_{2}\right)$, ammonium $\left.\left(\mathrm{NH}_{4}\right)_{2} \mathrm{CO}_{3}\right)$, potassium nitrate $\left(\mathrm{KNO}_{3}\right)$, calcium nitrate $\left(\mathrm{Ca}\left(\mathrm{NO}_{3}\right)_{2}\right)$, ammonium phosphate $\left.\left(\mathrm{NH}_{4}\right)_{3} \mathrm{PO}_{4}\right)$ and sodium nitrate $\left(\mathrm{Na}\left(\mathrm{NO}_{3}\right)\right)$ are major sources of nitrate ingression into the water and soil. Rapid growth of population has resulted in increasing use of azotic fertilizers to increase products. Plants are not able to absorb all nitrate available in soil. Depending on the type of plant and environmental conditions, plants absorb about 25 to 85 percent of the soil nitrate is absorbed. Therefore, a huge quantity of nitrate is not absorbed by plant and enters groundwater through penetration into superficial water(Hecnar, 1995). In regions having agricultural lands and use azotic chemical fertilizer to reinforce the ground, the amount of nitrate entering groundwater is 3 to 10 times more than regions in which chemical fertilizer is not used (National Research Council, 1955). Thus, expand studies shall be done to investigate the pollution of groundwaters by nitrate. It is usually very expensive or impossible to carry out all tests in largescale studies, therefore, numerical simulations should replace these tests. 


\section{Mineralizing nitrogen compounds}

Mineralizing nitrogen organic compounds is carried out in three steps include: becoming amino, making amino and producing nitrate. Certain microorganisms do the first two reactions and selffood producing bacteria in soil do the third reaction. These organisms need carbonated organic compounds for energy. Self-food producing organisms gain their energy from oxidation of mineral salts and their carbon from carbon dioxide present in the atmospheric. The certain of microorganisms include several groups of bacteria and fungi. Each of these groups is responsible for one or few stages of several disintegration reactions of organic substances. The final products of one group may be the raw material for the next group. This chain reaction continue till disintegration of the substance (Post, et al., 1996).

\section{Nitrate changes in water}

In newly polluted waters, the dominant form of nitrate is usually in organic nitrate (protein) form. As the time pasts, the nitrate changes into the ammoniac nitrate, and then into the nitrite under aerobic conditions and finally changes into the nitrate. After being absorbed and penetrating into the soil layers, the resulted nitrate enters groundwaters. The nitrate may change into the ammoniac nitrate under anaerobic conditions in deep layers. Waters newly polluted containing organic nitrate and ammoniac nitrate could cause more health disorders. Meanwhile, changes in the forms of nitrate in water depends on water $\mathrm{pH}$. Nitrate in waters having high levels of $\mathrm{pH}$ is normally in the form of ammonium compounds. Nitrate is seen in the form of free ammoniac in waters having low levels of $\mathrm{pH}$, which is very dangerous and concentration of more than 0.2 milligram per liter results in death of some living things. The maximum and minimum value of nitrate for drinkable water is 50 and $10 \mathrm{ppm}$. The suitable bound for drinkable water is 25 ppm. (Hecnar, 1995).

\section{Sine que non for supply matematical model}

Numerical models shall be equipped with standard tools for estimating the response of the well to changes in pumping rate, wells density and nitrate effects. In general, numerical solution of current in unsaturated environment having non-isotropic soils is studied. In order to include nitrate in governing equations, Porporate and Colleagues method has been presented (Porporato, et al.,2003). Organic substances and mineral nitrogen with five groups showing garbage, humus, ammoniac and nitrate are defined. Much interest in using finite volume method for preparing numerical models of groundwaters has been created during recent years. This method has local continuity for different applications in detaching operations. Finite volume method has been used for detaching mentioned equations in this paper (Morton and Suli, 1991). In order to assure that data for each model of groundwater are ratiocinative and show conditions of real current in aquatic layer, the model shall be calibrated. One of the most important ways of calibrating in wells in the region is calculating the amount of concentration or nitrate in some of the points of the model and evaluating them with laboratory results.

In general, organic substances in soil are divided into two groups. The first group is called humus, which are fairly resistant to disintegration. The second group disintegrates quickly. To disintegrate an organic substance by microorganisms, some nitrogen compounds are needed. The ratio of carbon to nitrogen is called $\mathrm{C} / \mathrm{N}$ ratio. This amount shows relative amounts of these two elements in fresh organic substance (humus) of the whole soil. The $\mathrm{C} / \mathrm{N}$ ratio of the stable organic substance in soil is about 10:1. Soil organisms, including bacteria and fungi, carry out mineralizing or making soil nitrogen organic.

Oxidizing carbonated substance present in soil satisfies their need for oxygen. Disintegration increases by increase in temperature. In addition, this reaction intensifies by sufficient but not much moisture in soil and sufficient oxygen. Disintegration is carried out in completely saturated condition (Birkinshaw and Ewen, 2000). Considering this action is the first step for preparing mathematical model. This study has been done in Mashhad on 2003.

\section{Materials and Methods Mathematical model}

Mathematical models of current in porous media shall have the ability to model the current by laplace relation and solution transfer equations. In this section, first laplace equation is solved by finite volume method. Then the general equation governing current in porous media is studied. The transfer of fluid having concentration and carrying minerals is expressed by following relation. The $\mathrm{q}$ variable is the velocity of the solution.

$\phi \partial(\rho c)+\nabla(\rho c q-\rho D \nabla c)=o$ 
Darcy Law defines this velocity.

$q=-\frac{k}{\mu}(\vec{\nabla} P-\rho \vec{g})$

The preliminary and boundary conditions shall be considered in mentioned relations. Total concentration variables $\mathrm{c}=\mathrm{c}(\mathrm{x}, \mathrm{t})$ and pressure $\mathrm{P}=\mathrm{P}(\mathrm{x}$, $t)$ shall be calculated. Required data and information include hollowness $\mathrm{k}=\mathrm{k}(\mathrm{x})$, viscosity $\mathrm{u}=\mathrm{u}(\mathrm{c})$, penetrability $\mathrm{k}=\mathrm{k}(\mathrm{x})$, tensor of dispersion distribution $\mathrm{D}=\mathrm{D}(\mathrm{x}, \mathrm{V})$ and gravity acceleration $\mathrm{g}$. The total concentration variable could be simulated on the basis of special concentration including nitrogen and carbon. To do so, carbon and nitrogen balance relations should be entered into the governing equations. Porporate presented carbon and nitrogen differential equation by mixing three equations for carbon and five equations for nitrogen. The correctness of the model has been confirmed in case study (D'Odorico, et al., 2003).

$\frac{d C_{t o t}}{d t}=A D D-r_{r} D E C_{1}-r_{r} D E C_{h}$

$\frac{d N_{t o t}}{d t}=\frac{A D D}{(C / N)_{a d d}}-L E^{+}-U P^{+}-L E^{-}-U P$

Variables in relations (3) and (4) show general decrease in system. The structure of presented model is similar to the model presented by Birkinsha and Iven(Birkinshaw and Ewen 2000). But in Birkinsha model, disintegration decrease has not been considered. Thus, carbon and nitrogen balance in Birkinsha model is not complete. ADD phrase is input from outside the system. This variable is the amount of remaining carbon added to the soil. It is possible that the amount and composition of surplus garbage varies in time depending on changes in plant life of bio-group. $\mathrm{DEC}_{1}$ shows carbon output gained from microbial disintegration. $\mathrm{DEC}_{h}$ shows output resulting from humus disintegration. The constant $r_{r}\left(0 \leq r_{r} \leq 1-r_{h}\right)$, shows the ratio of disintegrated organic carbon which enters breathing cycle $\left(\mathrm{CO}_{2}\right.$ production, it is estimated between 0.6 to 0.8 ). $\mathrm{LE}^{+}$ and LE are important for ammoniac and nitrate when the nitrogen solved in soil penetrates below the considered area. Finally, $\mathrm{UP}^{+}$and UP are the amount of ammoniac and nitrate absorption by plant (Porporato, et al.,2003).

\section{Discretization by finite volume method}

To form detached equations, equation 3 is integrated on controls volume. Figure 1 shows the volume of middle control.

Then Green relation is used and the effects of relations 4 and 5 on concentration are considered as source terms in calculations.

$$
\int_{A_{i}} \phi \frac{\partial \rho c}{\partial t} d x+\int_{\partial A_{i}} \rho c n \cdot q d s-\int_{\partial A_{i}} \rho n \cdot D \nabla c d s=\int_{A_{i}} Q d x
$$

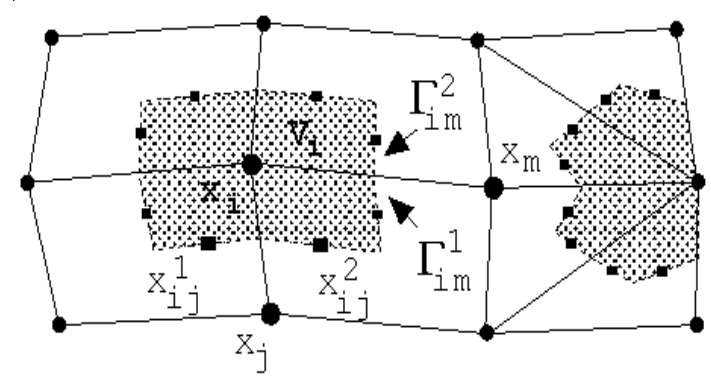

Figure 1: Considering element of middle volumes

$$
\begin{aligned}
& \int_{\partial A_{i}} \rho c n \cdot q d s-\int_{\partial A_{i}} \rho n \cdot D \cdot \nabla c d s \approx \sum_{j, e}\left|\Gamma_{i j}^{e}\right| n_{i j}^{e} . \\
& \left(\frac{1}{2} \rho_{i j}^{e} q_{i j}^{e}\left(c_{i}+c_{j}\right)-L_{i j}^{e} \rho_{i j}^{e} D_{i j}^{e} \nabla_{C_{i j}}^{e}\right)
\end{aligned}
$$

Integral relations on area $\mathrm{A}_{\mathrm{i}}$ are approximated in next step. To do so, the law of first rank approximation is used first. Boundary integral is approximated by following relation. In above relation, $\left|\Gamma_{\mathrm{ij}}^{\mathrm{e}}\right|$ is the size of part $\Gamma_{i j}^{e}$. Normal vector of area $A_{i}$ on part is shown by variable. Indexes of variables are shown as $j \in A_{i}$. The $\mathrm{j}$ affix is used for all nodes adjacent to $X_{\mathrm{i}}$. $e \in \mathrm{A}_{\mathrm{ij}}$. In case Scalier function is independent from local picklet number, $\mathrm{L}(0)=1$. An explanation for different approximation methods relying on Upwind is presented in $\mathrm{L}(0)>1$. The approximation used for $\mathrm{L}=1$ is done according to central difference. In order to shorten used signs,

$c_{i}=c_{h}\left(x_{i}\right), p_{i}=p_{h}\left(x_{i}\right), c_{i j}^{e}=c_{h}\left(x_{i j}^{e}\right), p_{i j}^{e}=p_{h}\left(x_{i j}^{e}\right)$

relations are used. Compound functions:

$\rho_{i}=\rho\left(c_{i}\right), \rho_{h}(x)=\rho\left(c_{h}(x)\right), \rho_{h}=\rho\left(c_{h}\right), \rho_{i j}^{e}=\rho\left(c_{i j}^{e}\right)$

are shortened by relations (Angermann, 1995). Then detached equation 7 is gained. 


$$
\begin{aligned}
& \left|A_{i}\right| \phi_{i} \partial_{t}\left(\rho_{i} c_{i}\right)+\sum_{j, e}\left|\Gamma_{i j}^{e}\right| n_{i j}^{e} \cdot\left(\frac{1}{2} \rho_{i j}^{e} q_{i j}^{e}\left(c_{i}+c_{j}\right)-\right. \\
& \left.L_{i j}^{e} \rho_{i j}^{e} D_{i j}^{e} \nabla_{C_{i j}}^{e}\right)=\left|A_{i}\right| Q_{i}
\end{aligned}
$$

The same is done for current equation. Thus, the solution is changed into semi-continuous. Then the $\left(\mathrm{C}_{\mathrm{h}}(\mathrm{t}), \mathrm{P}_{\mathrm{h}}(\mathrm{t})\right)^{\mathrm{a}} \mathrm{V}_{\mathrm{h}}=\mathrm{V}_{\mathrm{h}} \times \mathrm{V}_{\mathrm{h}}$ values are achieved. Similar issues are true for all modes of $\mathrm{t}^{\mathrm{a}}(0, \mathrm{t})$. The carbon and nitrogen relation is defined by introducing Porporate model. Debidarssi is defined in equation 2. Finally the system is solved by euler detaching implicit function.

\section{Case study}

Case study has been done to investigate the correctness of designed model. Mashad plain has been used for case study. Topographic data, soil specifications, and solid part of porous media are among data required for modeling. Piezometric data of removed pressure is also required for defining preliminary conditions. Preliminary data have been provided through correspondence and personal meetings with Mashad Regional Water Company. Some of the achieved data didn't have necessary standard from statistical and environment type description viewpoints. These suspicious data were reviewed and calibrated studying maps of Mashad plain area; physical dimensions of the area for study were determined and defined to the model. In the mid part of studied area, Mashad city and its western part up to Vakilabad bridge are extended. As the studies revealed, the studied area is not penetrable from south and west. Complementary studies for defining specifications of hydrodynamic coefficients have been done by Mashad regional water. The concentration of nitrate is defined to the model as preliminary conditions and concentration boundary. Necessary specifications of the basin are defined to the model in the next stage. The prepared mathematical model shall be calibrated. Time and spatial dispersion of basin features parameters shall also be considered in calibration stage. After calibration, results correctness, their control, future planning and foreseeing are done. Figure 2 shows nodding in Mashad plain. Mashad plain is divided into 952 nodes and 812 finite volumes. Figure 3 shows volume division of this plain and the locations of nodes 14,485 and 876 . The reason of selection these joints are investigation the various part of Mashhad plain that these joints situated at various regions. Simulated quantities of the changes in nitrogen during
1991 to 2003 compared with laboratory-measured amounts on node 14 are shown in Figure 4. As it is seen, the differences between numerical and measured quantities are insignificant after calibration. Figure 5 shows calculated and numerical quantities on node 876. Figure 6 shows changes in nitrate in above-mentioned nodes by using finite volume approach. Figure 7 shows numerical values of the nitrogen that calculate by finite volume and finite element technique on node 14 during 1991 to 2003.

\section{Discussion and Conclusion}

Authors of this paper have carried out numerical works for several years and have applied different underground water methods like TRUST, TRUMP, PORFLOW, UNSAT, SUTRA, MODFLOW and etc., on several fields in Iran. Authors have designed FVMP model to solve problems of available underground water models. This model has been designed based on mathematical model and current discretization by finite volume method. The objective of designing this program is to solve several problems in relation to simulation of current in porous media. Main features of the code include:

- Simulation of advective, dispersive, diffusive transport in up to two dimension using the global implicit option or three dimensions using time splitting of transport and reaction.

- Non-isothermal transport and reaction

- Multi-component aqueous complexation

- Kinetically-controlled mineral precipitation and dissolution

- Multi-component exchange on multiple sites

- Multi-component diffusion with an electrochemical migration term to correct for electro neutrality where diffusion coefficients of charged species differ.

- Unstructured spatial grids (triangles / quadr laterals)

- Variable time step sizes

- Schemes of different order in space /time

Every groundwater flow model must be calibrated to ensure that it is a reasonable representation of the actual flow conditions in the aquifer. One of the most common means of calibration wells in the field is to calculate water quality for those points in the model. In this way, the validity of the modeling results can be assessed and the model credibility as a predictive tool can be established. The above mentioned model (FVMP) has been calibrated by different methods and its 


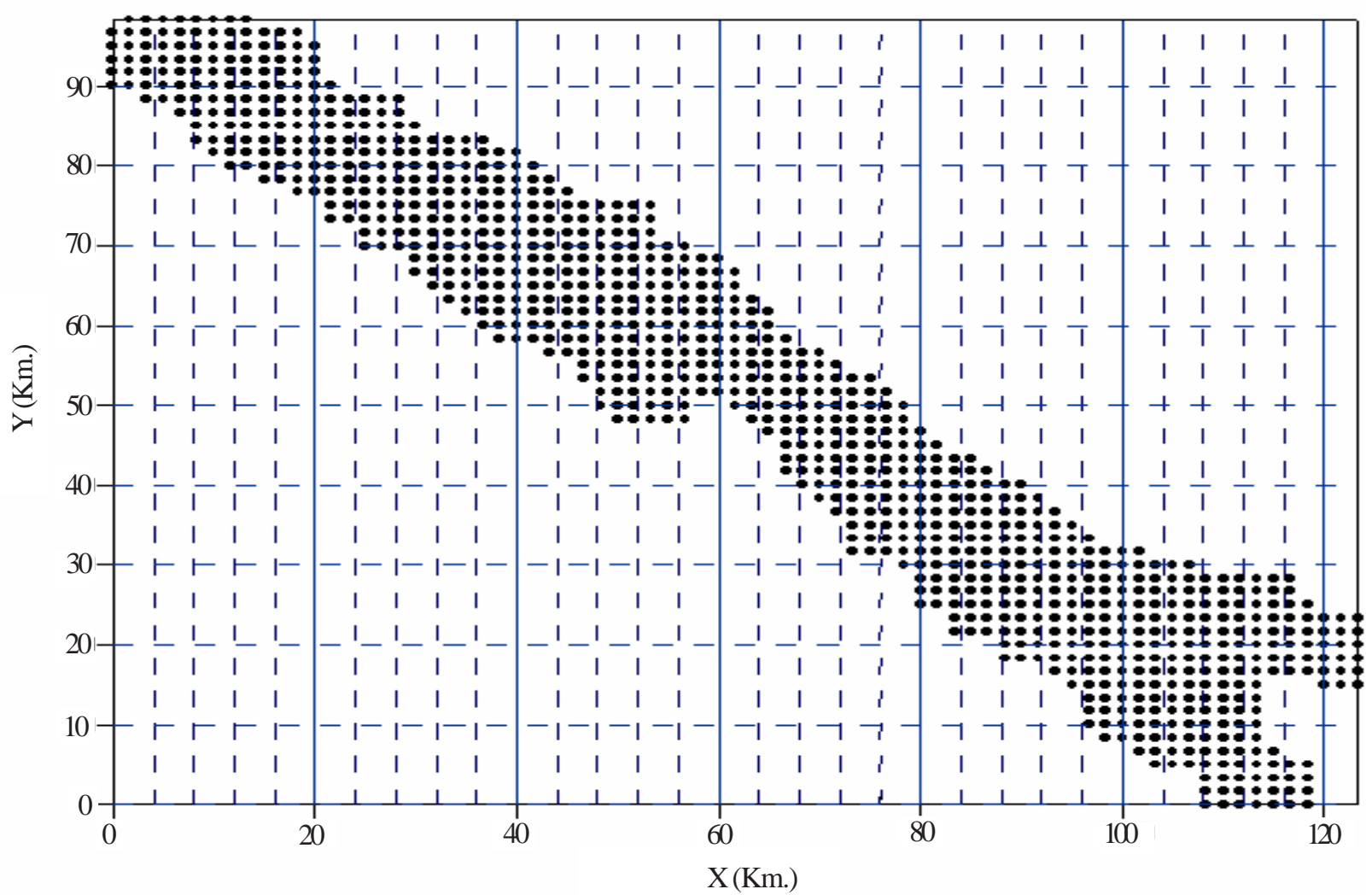

Figure 2: Nodding in Mashad plain

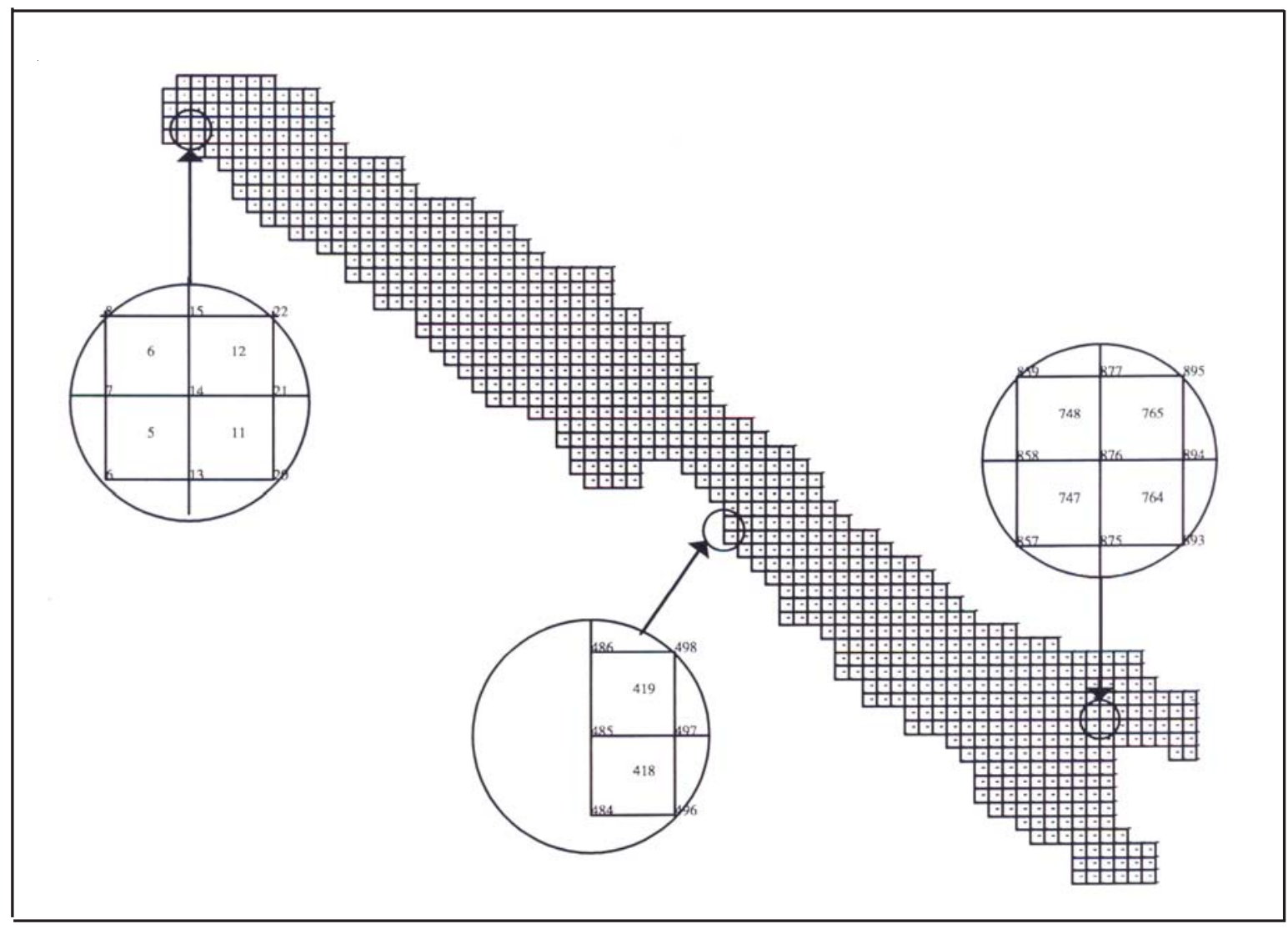

Figure 3: Volume division of this plain and the locations of nodes 14, 485 and 876 


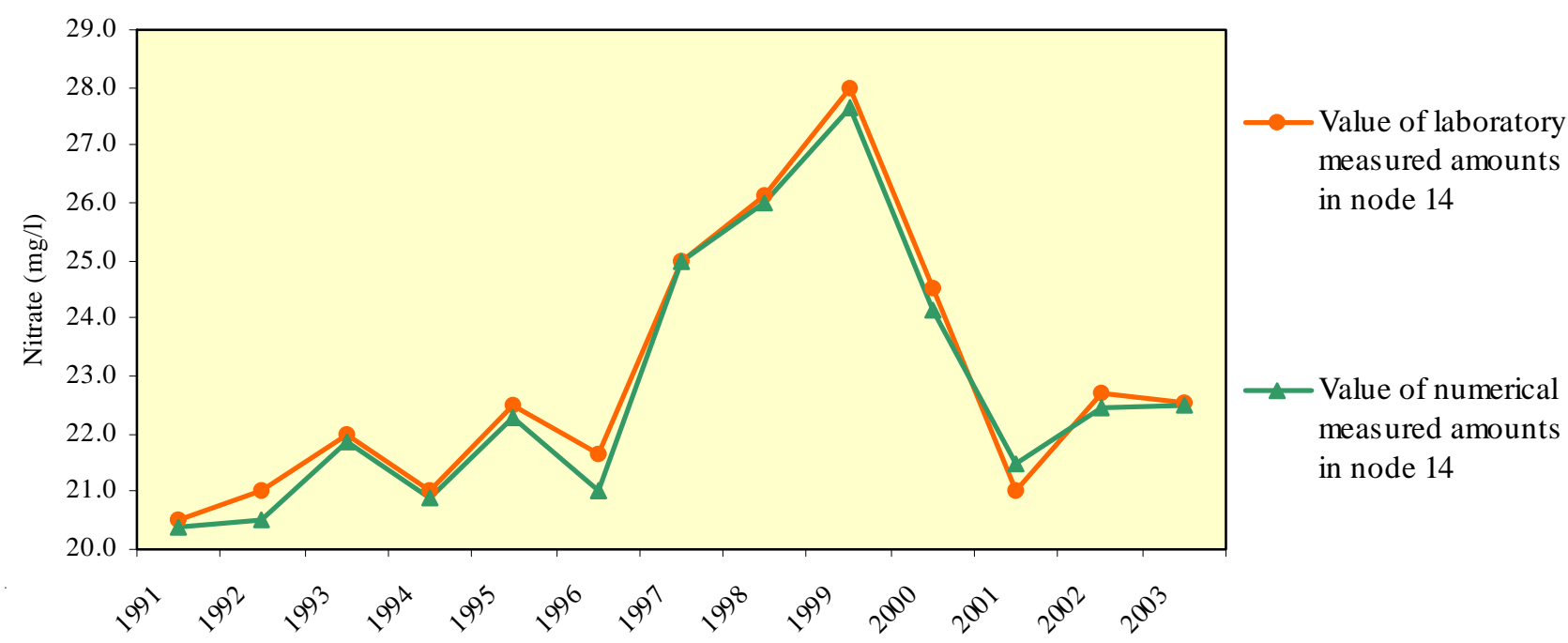

Figure 4: Numerical and laboratory values of the nitrogen on node 14 during 1991 to 2003

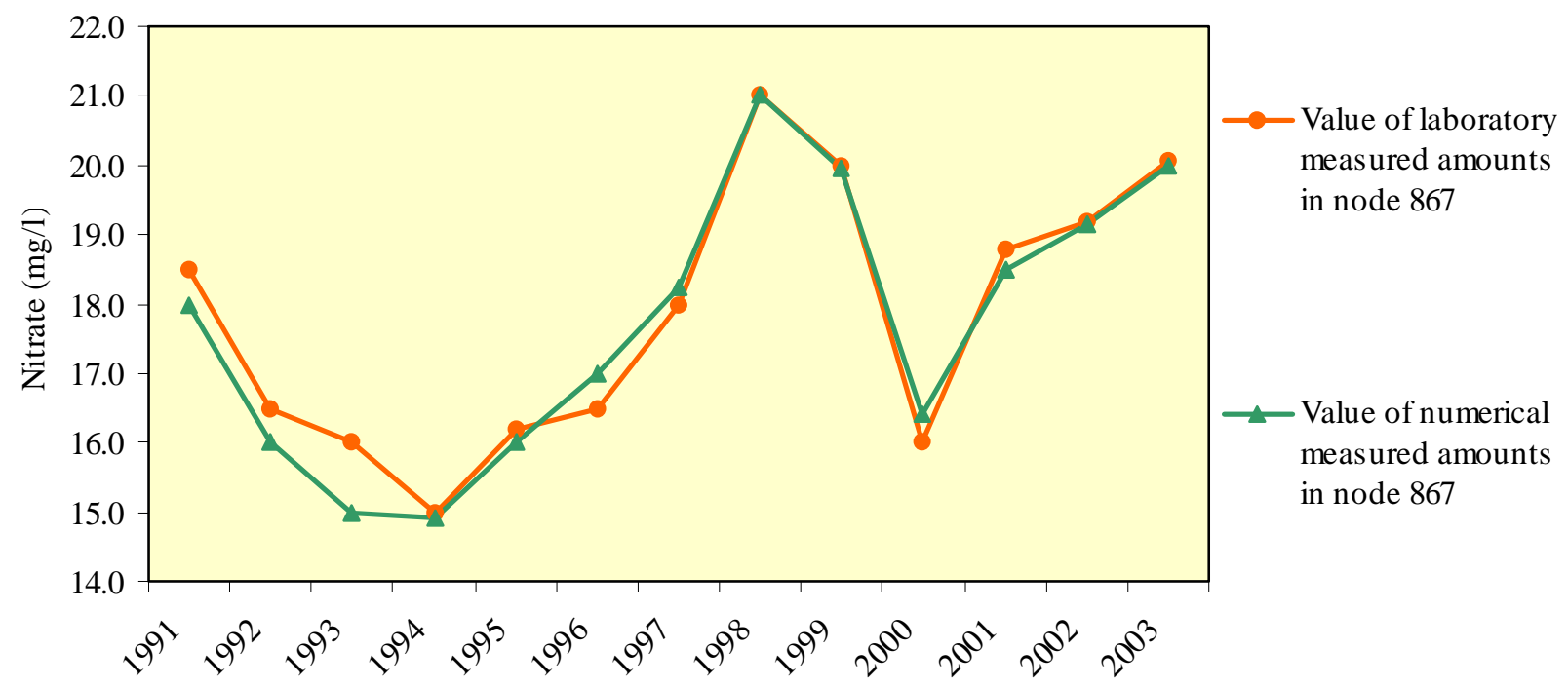

Figure 5: Numerical and laboratory values of the nitrogen on node 876 during 1991 to 2003

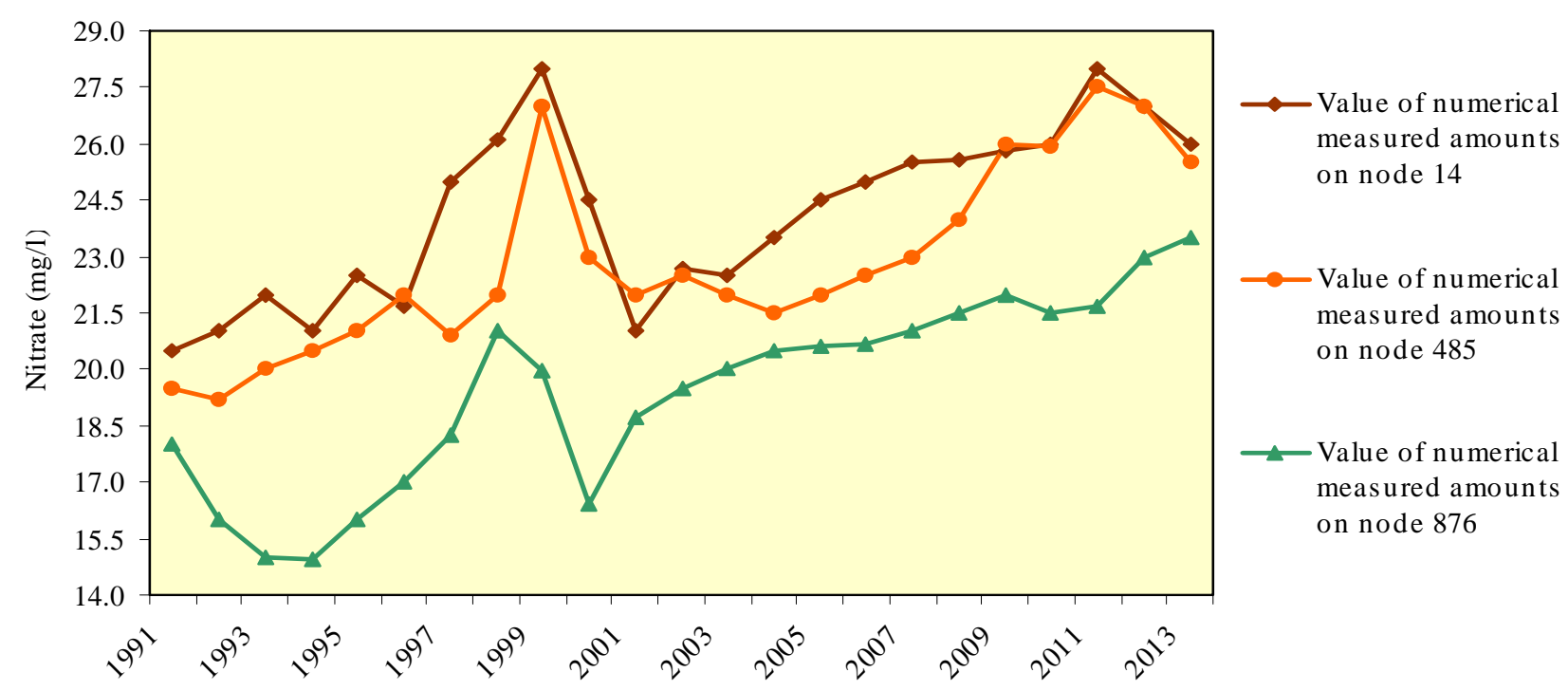

Figure 6: Simulation changes in nitrate in different nodes by using finite volume approach 


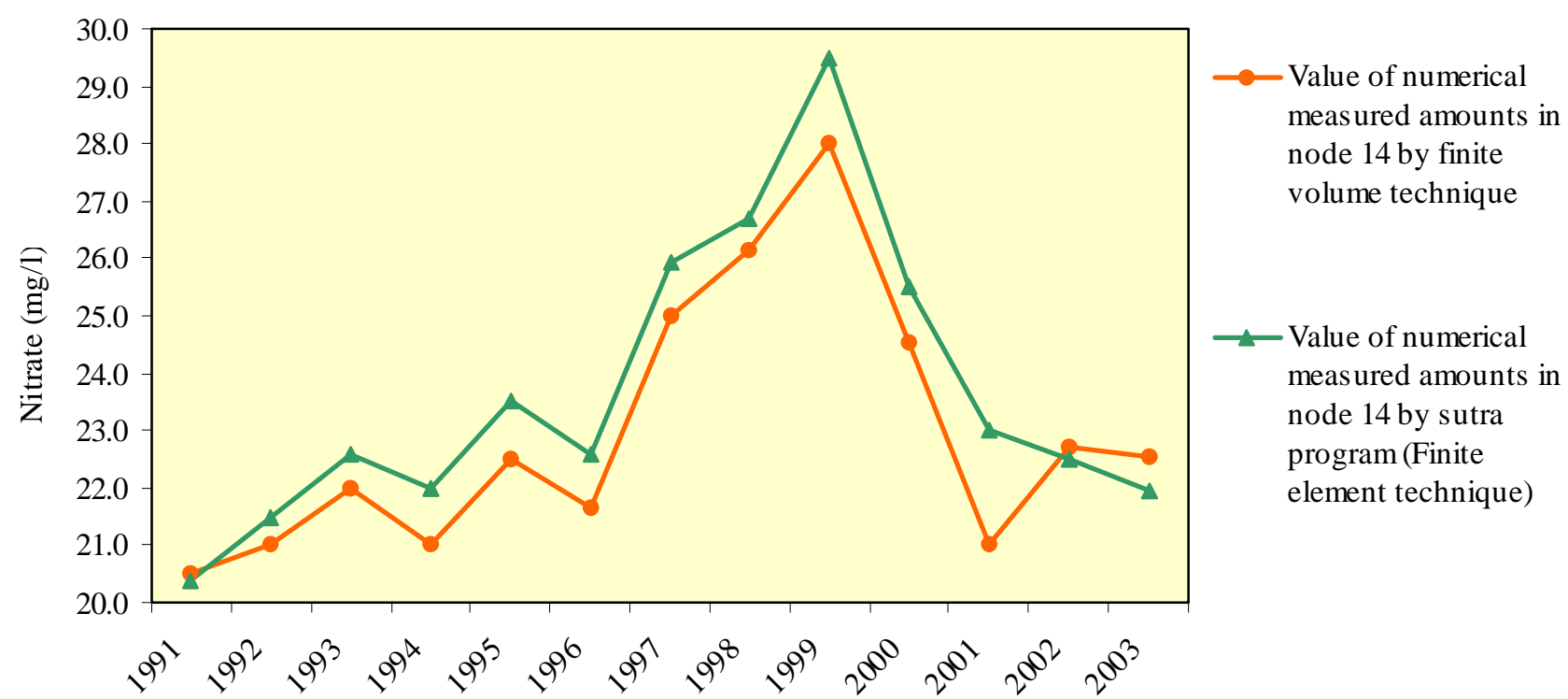

Figure 7: Numerical values of the nitrogen that calculate by finite volume and finite element technique on node 14 during 1991 to 2003

correctness has been certified. Figure 7 shows that, the difference between finite volume and finite element approach is less than 6.5 percent. Figure 4 shows that, the difference between finite volume and laboratory values is less than 0.3 percent. Therefore the finite volume approach is recommended for discretization of flow contain nitrate in porous media.

- The important advantage of finite volume method compared with finite element and finite difference methods is in capability of defining boundaries of studies regions. As it is observed in the case study, boundaries of studied plain are defined to the model easily and without using many volumes. The presented mathematical model for simulating nitrates in porous environments, which is a mixture of separated models, has appropriate accuracy.

- Comparing changes in Figures 4 and 5 show that, it is possible to achieve acceptable accuracy by using finite volume technique in simulating nitrogencontaining current.

- It is possible to make forecasts by using results of presented model concerning changes in nitrate in time. Using these forecasts, the state of drinking waters is determined for several years.

- Figure 6 shows that, the quality of drinking water of Mashad Plain is suitable for the next ten years.

\section{References}

Angermann, L., An upwind scheme of finite volume type with reduced crosswind diffusion. Technical Report 165, Institut for angewandte mathematic, University Erlangen , 1995
Birkinshaw, S. and J. Ewen, Nitrogen transformation component for shetran catchment nitrate transport modelling. J. Hydrology, 230:1-17, 2000

D’Odorico, P., F. Laio, A. Porporato and I. RodriguezIturbe, Hydrologic controls on soil carbon and nitrogen cycles. II. A case study, Advances in Water Resources, 26: 59-70, 2003

Hecnar, S. J., Acute and chronic toxicity of ammonium nitrate fertilizer to amphibians from southern Ontario. Environmental toxicology and chemistry, 14 (12): 2131 - 2137, 1995

Morton, K. W. and E. Suli, Finite volume methods and their analysis. J. Numer.Anal., 11: 241-260, 1991

National Research Council, Nitrate and nitrite in drinking water, Washington, D.C., National Academy Press, 1955

Post, W., A. King and S. Wullschleger, Soil organic matter models and global estimates of soil organic carbon, In: Powlson Ds., Smith P., Smith JU, editors. Evaluation of soil organic matter models, vol of NATO ASI. Berlin, Germany: Springer Verlag,: 38: 201-222, 1996

Porporato, A., P. D’Odorico, F. Laio and I. RodriguezIturbe, Hydrologic controls on soil carbon and nitrogen cycles. I. Modeling scheme, Advances in Water Resources, 26: 45-58, 2003

Rademach, J., T. B. Young and M. S. Kanarek, Gastric cancer mortality and nitrate levels in Wisconsin drinking water. Arch Environ Health, 47, 1992 